\title{
Targeted therapy of chronic myeloid leukemia
}

\author{
Con Sullivan ${ }^{1}$, Cong Peng ${ }^{2}$, Yaoyu Chen², Dongguang $\mathrm{Li}^{3}$, and Shaoguang $\mathrm{Li}^{2}$, \\ ${ }^{1}$ Maine Institute of Human Genetics and Health, 246 Sylvan Road, Bangor, ME 04401, USA \\ 2Division of Hematology/Oncology, Department of Medicine, University of Massachusetts Medical \\ School, 364 Plantation Street, Worcester, MA 01605, USA \\ ${ }^{3}$ School of Computer and Security Science, Edith Cowan University, 2 Bradford Street, Mount \\ Lawley, WA 6050, Australia
}

\begin{abstract}
Inhibition of BCR-ABL with kinase inhibitors has become a well-accepted strategy for targeted therapy of Philadelphia-positive $\left(\mathrm{Ph}^{+}\right)$chronic myeloid leukemia (CML), and has been shown to be highly effective in controlling the disease. However, BCR-ABL kinase inhibitors do not efficiently kill leukemic stem cells (LSCs), indicating that this therapeutic strategy does not lead to a cure of CML. Development of curative therapies of CML require the identification of genes/ pathways that play critical roles in survival and self-renewal of LSCs. Targeting of these key BCR-ABL downstream genes provides an opportunity to eradicate LSCs, as shown in our work that identifies the Alox5 gene as a key regulator of the function of CML LSCs. Immediate clinical trials are necessary to test the effectiveness of targeting a key BCR-ABL downstream gene in eradicating LSCs in CML patients. In this review, we will discuss current targeted therapies of CML using BCR-ABL kinase inhibitors, with a focus on the importance of developing a targeted therapy of CML through identification of target genes in CML LSCs.
\end{abstract}

\section{Keywords}

BCR-ABL; kinase inhibitor; leukemia stem cells; CML; targeted therapy

\section{Myeloproliferative neoplasms}

\begin{abstract}
Myeloproliferative neoplasms (MPN), as defined by the 2008 World Health Organization (WHO) revised classification, represent a distinct subset of myeloid neoplasms and acute leukemias that also include acute myeloid leukemia (AML); myelodysplastic syndromes (MDS); MDS/MPN; and myeloid neoplasms associated with eosinophilia and abnormalities of PDGFRA, PDGFRB, or FGFR1 [1-3]. They are typified by aberrant clonal expansion,
\end{abstract}

\footnotetext{
(C) 2010 Elsevier Inc. All rights reserved

*Correspondence: Shaoguang Li, University of Massachusetts Medical School, Department of Medicine, 364 Plantation Street, Worcester, MA 01605; Tel: 508-856-1691, Fax: 508-856-7969; shaoguang.li@umassmed.edu..

Publisher's Disclaimer: This is a PDF file of an unedited manuscript that has been accepted for publication. As a service to our customers we are providing this early version of the manuscript. The manuscript will undergo copyediting, typesetting, and review of the resulting proof before it is published in its final citable form. Please note that during the production process errors may be discovered which could affect the content, and all legal disclaimers that apply to the journal pertain.
} 
which is usually attributable to a chromosome rearrangement or a point mutation that leads to the constitutive activation of proliferative signal transduction pathways. These genomic instabilities, both at the chromosomal and microsatellite levels, are inextricably linked to disruptions in apoptotic pathways and ultimately the development of assorted cancers [4].

Human Philadelphia chromosome-positive $(\mathrm{Ph}+)$ leukemias are a type of MPN that results from a structural chromosomal instability caused by the translocation of a portion of chromosome 22 on to chromosome 9 (t[9,22]). This translocation leads to the fusion of the Breakpoint Cluster Region (BCR) gene to the Abelson Tyrosine Kinase (ABL1) protooncogene and the formation of the $B C R-A B L I$ oncogene. Three major variants of the $B C R$ $A B L 1$ oncogene exist and arise from breaks introduced at exon 1 (encoding the P190 isoform), exon 12/13 (encoding the P210 isoform), or exon 19 (encoding the P230 isoform) of $B C R$. The $B C R-A B L$ oncogenes encode constitutively-active non-receptor tyrosine kinases capable of transforming hematopoietic stem cells (HSCs) and causing leukemias [5]. BCR-ABL1 is responsible for $95 \%$ of all diagnosed chronic myeloid leukemia cases and up to $30 \%$ of acute lymphoblastic leukemias (ALL) diagnosed in adults. For CML, the disease course typically unfolds in three stages. The chronic stage, prior to the advent of modern molecular therapies, lasted three to five years and was characterized by leukocytosis, with particular increases in the numbers of neutrophils. Eventually, the disease progressed through an accelerated phase to the blast crisis phase. This transition from chronic to the accelerated and blast phases is presumed to occur due to secondary genetic changes. The blast phase resembles acute leukemia and, left untreated, is quickly fatal (within 6- 12 months).

Human $\mathrm{Ph}$ chromosome-negative ( $\mathrm{Ph}-)$ neoplasms constitute the remainder of the MPNs, which include polycythemia vera (PV), essential thrombocythemia (ET), and primary myelofibrosis (PMF), among others. Often these $\mathrm{Ph}-$ neoplasms contain mutations in the Janus Kinase 2 (JAK2) gene (e.g. JAK2V617F) or the Myeloproliferative Leukemia Virus $(M P L)$ (e.g. $M P L W 515 \mathrm{~L} / \mathrm{K})$ gene and can be determinative of the type of MPN when complemented with the relevant histologies. The JAK2V617F mutation is the most commonly seen in $\mathrm{Ph}$ - neoplasms and is strongly associated with PV (>90\% of patients). Occurring in the pseudokinase $\mathrm{JH} 2$ domain of the protein, this mutant is devoid of the normal protein's autoinhibitory capacity, resulting in a constitutively-active kinase capable of triggering cellular hypersensitivity to cytokines and eventual pathology [6-8]. Gain-offunction mutations in exon 12 of $J A K 2$ are the next most common in patients with PV and idiopathic erythrocytosis [9] The $M P L$ gene encodes the thrombopoietin receptor, and mutations in this protein at residue $515(M P L W 515 \mathrm{~L} / \mathrm{K})$ have usually been associated with PMF $[10,11]$. The mutation is believed to trigger a G1/S transition, thereby disrupting the cell cycle and promoting the neoplasm [11].

\section{The BCR-ABL Oncoproteins}

The Ph chromosome was discovered in 1960 by Hungerford and Nowell [12] and later recognized by Rowley to be the result of a chromosomal translocation [13]. Chromosomal translocations are a type of chromosomal rearrangement that can occur. Others include inversions, deletions, and the formation of episomes. Each of these can result in the 
formation of chimeric fusion genes or the dysregulated expression of normal genes and the onset of malignancy, particularly but not exclusively of hematological origins [14, 15]. The $\mathrm{Ph}$ chromosome is the archetypal chromosomal translocation and has been associated with chronic myeloid and B cell ALL (CML and B-ALL, respectively). Its formation leads to the fusion of the $B C R$ and $A B L 1$ genes, usually in one of three isoforms (encoding P190, P210, or P230) and results in the formation of a constitutively-active tyrosine kinase. Both the BCR and ABL1 moieties of the BCR-ABL1 oncoproteins contribute important structural components that are essential to its function. For example, the SRC-homology 1 (SH1) domain within the ABL1 portion contributes the tyrosine kinase activity that is central to BCR-ABL1 function. The ABL1 portion also possesses a SH2 domain that facilitates protein-protein interactions, an actin-binding domain, a DNA binding domain, a nuclear localization motif, and a nuclear export motif [16]. Despite the presence of these nuclear signal sequences, BCR-ABL expression is cytoplasmic. The BCR portion contributes a coiled-coil domain that is required for dimerization and a tyrosine residue at position 177 that is essential for the binding of adaptor proteins, including Growth Factor ReceptorBound Protein 2 (GRB2) GRB10, 14-3-3, and the SH2 domain of ABL1, and subsequent constitutive activation $[16,17]$. Among the three isoforms, $\mathrm{P} 210$ and $\mathrm{P} 230$ possess additional protein domains that may contribute to the leukemic phenotype and distinguish them from P190 [18, 19]. Specifically, P210 and P230 both possess the pleckstrin homology $(\mathrm{PH})$ domain, which enables these BCR-ABL1 isoforms to interact with novel protein partners like PLCE, Zizimin1, tubulin and SMC1 [19], and the differentiated B-cell lymphoma (DBL) domain, which functions as a guanine exchange factor for the RHO GTPases [20]. All BCR-ABL1 oncoproteins have broad effects on numerous pathways through kinase-dependent and surprisingly kinase-independent pathways. Dysregulation of these pathways by BCR-ABL1 leads to leukemic phenotypes that result from altered capacities to adhere, control proliferation, and induce apoptosis. The type of $\mathrm{Ph}+$ leukemia that ensues is largely dependent upon the isoform that is created by the break and fusion [17, 21]. The P210 isoform predominates and is associated with most cases of CML and about one-third of the cases of B-ALL. The less common P190 isoform accounts for the remaining two-thirds of B-ALL and only small number of CML cases. Its propensity to trigger acute leukemia is attributed to its higher tyrosine kinase activity [22-24]. The P230 isoform, which has weaker intrinsic kinase activity than P190 and P210 isoforms, has been associated with rare chronic neutrophilic leukemias [25], although the reason may have more to do with individual genetic dispositions or selection biases rather than a weaker proliferative capacity [24]. There have several reports of showing individuals expressing the P230 isoform developing typical CML [24, 26-30].

\section{BCR-ABL1 Kinase-Independence}

The potent, constitutively-active non-receptor tyrosine kinase activities of the BCRABL1 oncoproteins are responsible for triggering assorted signaling pathways that promote the growth and survival of hematopoietic cells and the induction of cell transformation. These pathways include those mediated by Ras, mitogen-activated protein kinase (MAPK), c-jun $\mathrm{N}$-terminal kinase (JNK)/ stress-activated protein kinase (SAPK), nuclear factor kappa-lightchain-enhancer of activated B cells (NF- $\kappa \mathrm{B})$, signal transducers and activators of 
transcription (STAT), phosphoinositide 3- (PI-3) kinase, and c-Myc, among others. Early enthusiasm that the targeting of BCR-ABL1 kinase activity could provide curative therapy has been tempered by the realization that not all BCR-ABL1-expressing cells are killed using kinase-inhibiting drugs like imatinib and that targeted kinase inhibition has limited, if any, impact on patients entering blast crisis or presenting with B-ALL. Indeed, there is now recognition that targeted approaches to the kinase-independent signaling pathways of BCRABL1 are just as important. For example, BCR-ABL can activate members of the SRC family kinases (SFKs) through a kinase-independent mechanism. The eight members of the SFK family (Src, Blk, Fgr, Fyn, Hck, Lck, Lyn, and Yes) function as non-receptor tyrosine kinases important to cell growth, differentiation, and survival. Several members are expressed in hematopoietic cells and have been implicated in myeloid and lymphoid leukemias [31, 32]. Fyn and Lck are expressed in T cells, while Blk, Fgr, Fyn, and Lyn are known to be expressed in B cells. Myeloid cells express Fgr, Hck, and Lyn [31, 32]. BCRABL1 is known to increase the activity of Lyn and Hck in hematopoietic cells [33], and in turn, the SFKs Hck, Lyn, and Fyn have been shown to phosphorylate tyrosine residues within the SH3-SH2 domains of BCR-ABL1 [34]. Our laboratory has shown that the BCRABL kinase-independent activation of the SFKs Lyn, Hck, and Fgr is essential for the transition of chronic phase CML to lymphoid blast crisis using our mouse model [35, 36]. In addition, we have shown that inhibition of BCR-ABL kinase activity by imatinib fails to control B-ALL in our mouse model, while inhibition of both BCR-ABL kinase activity and SFKs by dasatinib does [36]. In imatinib resistance, SFKs are speculated to take on a more specialized role. For example, the SFK Lyn is activated in imatinib-resistant CML cells and regulates the tyrosine phosphorylation of BCR-ABL1 itself and Gab2, contributing to cell survival. BCR-ABL1 phosphorylation by SFKs is believed to facilitate binding to GRB2, which activates the MEK/ERK signaling pathways. Lyn can also complex with c-Cbl and negatively regulate its stability, thereby potentially affecting its capacity to transform cells [37]. In another study, both Lyn and Hck were upregulated in imatinib-resistant blasts derived from CML patients [38]. It is believed that SFK expression ultimately becomes independent of BCR-ABL1 expression as disease progresses, and this may in part account for the difficulties observed once the disease transitions from the chronic phase into the accelerated and blast phases [32].

\section{Mouse Models for Human $\mathrm{Ph}+$ Leukemias}

The faithful recapitulation of human hematological malignancies using mouse models has greatly enhanced our understanding of these diseases. Numerous experimental approaches have been devised to model $\mathrm{Ph}$ + leukemias in mice including transgenic mice expressing human BCR-ABL1, gene knock-ins expressing BCR-ABL driven from a specific locus (e.g. $\mathrm{E} \mu, \mathrm{BCR}$ and metallothionein), targeted and conditional gene knockouts (including ICSBP), and the engraftment of human BCR-ABL1-expressing cells in immunodeficient mice. These approaches have previously been reviewed [39-42]. None of these models has proved more effective than the retroviral transduction and transplantation model introduced in the early 1990s [43, 44] and subsequently improved to cause 100\% incidence of CML-like and BALL in mice of varying backgrounds (C57BL/6, Balb/c, etc.) [24]. We have recently described our retroviral transduction and transplantation model for the induction of CML 
[45]. Briefly, donor mice are treated with 5-fluorouracil to enrich for c-kit ${ }^{+} / \mathrm{Scal}^{+} / \mathrm{Lin}^{-}$stem cells. Donor mice are sacrificed and bone marrow cells are harvested from the tibias and femurs. Cells are stimulated overnight in culture media supplemented with IL3, IL6, SCF, and WEHI-conditioned media. Cells are then subjected to two rounds of retroviral transduction via spin infection in the presence of IL3, IL6, SCF, and WEHI-conditioned media. Viruses express GFP to serve as a marker of infection and the P210 isoform of BCRABL1. They are high-titer, replication-incompetent, and capable of high infectivity. Transduced cells are injected into irradiated syngeneic or immunocompromised recipients, and the development of disease is monitored through FACS of peripheral blood (GFP+ and Gr1+ or Mac1+) and visual observation (morbidity, weight loss, failure to thrive, and splenomegaly). For B-ALL, cells from donor mice are harvested without 5-fluorouracil treatment, subjected to one-round of transduction with a GFP+ expressing, BCR-ABL1expressing retrovirus (P190 or P210), and transplanted into irradiated syngeneic or immunocompromised recipients. Disease development is tracked via FACS of peripheral blood (GFP+ and B220+) and visual observation (morbidity, failure to thrive, pleural effusion, and resultant dypsnea).

\section{Development of Intractable Resistance to Anti-Ph+ Leukemic Therapy}

$\mathrm{Ph}+$ leukemias are highly dependent upon the kinase activities of the BCR-ABL oncoproteins that cause them. As a result, the constitutively-active kinase activity of BCRABL1 oncoprotein has served as an attractive target for therapeutic intervention. A panel of inhibitors was developed in an attempt to quell the tyrosine kinase activities of BCR-ABL, PDGFR, and others. In particular, the inhibitors chosen belonged to a class of compounds capable of competing for the ATP binding pockets of kinases known as 2-

phenlyaminopyrimidines. Of these compounds, the most promising was signal transduction inhibitor (STI) 571, which later become known as imatinib or the brand name Gleevec (Glivec in Europe). Imatinib binds an inactive conformation of the BCR-ABL1 oncoprotein by targeting the conserved nucleotide-binding pocket of ABL and stabilizing it, thereby preventing it from phosphorylating downstream effector molecules [46]. Imatinib is now established as the front-line therapy for CML, consistently producing complete hematogical responses for those in the chronic phase of the disease, despite the fact it does not completely eliminate all BCR-ABL1-expressing cells [47, 48]. Unfortunately, it is less effective in controlling $\mathrm{Ph}+\mathrm{CML}$ in blast crisis and in Ph+ B-ALL [49], indicating a BCRABL1 kinase-independent component. In addition, imatinib resistance has become a serious issue, increasing at a rate of $4 \%$ per year [50]. Resistance most often originates as a consequence of mutations in the kinase domain of BCR-ABL1, with one survey noting a 90\% correlation [51]. These mutations are thought to induce resistance by disruption of amino acids that contact imatinib or by the prevention of the formation of the inactive conformational state [51]. The most intractable of these occurs at the threonine residue 315. Missense mutations in this "gatekeeper" residue most often convert this amino acid to an isoleucine. The T315I mutation is responsible for $\sim 20 \%$ of all cases of imatinib resistance [52]. This gatekeeper threonine is common to many tyrosine kinases (v-SRC, c-SRC, cABL, EGFR, PDGFRA, PDGFRB, and c-Kit) and its mutation has been shown to enhance their kinase and transformation activities [52]. The mechanism by which the T315I mutation 
is thought to confer resistance is the subject of intense investigation. Azam et al. [52] provide compelling evidence for the notion that the mutation of the gatekeeper position from threonine can stabilize BCR-ABL1 within its hydrophobic spine [52], which binds disparate portions of the molecule through these hydrophobic interactions and stabilizes the active kinase [52, 53]. Mian et al. [54] provide evidence that the T315I mutant also possesses enhanced leukomogenic potential. Using loss-of-function mutants, they show BCR-ABL1 T315 mutants are autophosphorylated at the T177 position, which facilitates its oligomerization; can thrive in the absence of growth factors; and can phosphorylate endogenous BCR. The eventual selection of imatinib-resistant mutants, particularly the T315I mutant, in combination with its diminished efficacy in patients in Ph+ CML blast crisis or with $\mathrm{Ph}+\mathrm{B}-\mathrm{ALL}$, has made the development of alternative therapeutic approaches necessary.

Dasatinib (Sprycel) is at the forefront of the second-generation of anti-leukemia drugs currently going through clinical trials. Dasatinib has a broader anti-kinase activity than imatinib, dually inhibiting both BCR-ABL1 and downstream SRC family kinases and has proven utility against imatinib-resistant leukemias (excluding T315I) as well as $\mathrm{Ph}+\mathrm{CML}$ in accelerated phase and blast crisis and $\mathrm{Ph}+\mathrm{B}$-ALL [50]. Dasatinib has a higher binding affinity for the BCR-ABL1 kinase ATP pocket and is able to interact with the protein in multiple conformation states (active and inactive) [55]. This property starkly contrasts with imatinib and most likely accounts for its enhanced activity. Its efficacy against many mutant forms of BCR-ABL1, excluding T315I, has been attributed to its ability to bind in a way that is independent of these mutant residues. Dasatinib and imatinib also appear to have differential response to multidrug resistance pumps which Talpaz et al. speculated may allow for higher intracellular concentrations of the dasatinib in leukemic cells [56]. However, a recent study confounds this argument, with imatinib and nilotinib, another second-generation drug, showing a greater capacity to inhibit efflux through MRP7 (ABCC10) than dasatinib [57]. These studies were performed using HEK293 cells, rather than leukemic cells, and the retention of other cancer drugs was tested. The ability of dasatinib to inhibit SRC family kinases (SFKs) broadens its therapeutic power. BCR-ABL1 is known to activate the SFKs LYN and HCK in human myeloid cell lines (K562, BV173, and LAMA84) [33] and can activate LYN, HCK, and FGR in a mouse model for Ph+ BALL [35]. This activation is independent of BCR-ABL kinase activity and supports a kinase-independent model of BCR-ABL1-mediated leukemogenesis involving SFKs like LYN, HCK, and FGR [35, 36, 58-60]. The ability to inhibit SFKs appears not to affect the course of the chronic-phase CML but rather is of importance in Ph+ B-ALL and the transition to lymphoid blast crisis from the chronic phase of CML [35, 36]. Taken together, dasatinib is a more effective agent for the control of chronic-phase CML, with 325-fold more kinase-inhibiting activity than imatinib, as measured by its ability to inhibit Ablcatalyzed peptide substrate phosphorylation [61]. It also exhibits novel properties that make it useful for Ph+ lymphoid manifestations like B-ALL and lymphoid blast crisis

Nilotinib (Tasigna) is a second-generation tyrosine-kinase inhibitor designed to improve upon imatinib and is intended for use in CML chronic and accelerated phase patients upon the development of imatinib resistance [62]. Like imatinib, nilotinib solely inhibits BCR- 
ABL1 kinase activity by binding the protein in its inactive conformation; however, the developers also incorporated alternative binding groups to the $N$-methylpiperazine moiety to improve the interaction between the drug and kinase binding site, leading to 10-30-fold more potent drug. Clinical trials indicate efficacy in imatinib-resistant cases, with high rates of hematological and cytogenetic responses observed [62].

Despite these exciting advances, outstanding questions remain with regard to $\mathrm{Ph}^{+}$leukemia progression. The introduction of promising new drugs like dasatinib, which has been approved by the U.S. Food and Drug Administration (FDA), and nilotinib, which is in the pipeline along with several others, will offer good alternatives to control disease in certain resistance cases [50]. Other resistant cases, particularly arising from the T315I mutation, are especially difficult. Despite these setbacks, a new class of pharmaceuticals known as aurora kinase inhibitors (AKIs) offer particular hope. While not yet FDA-approved, AKIs like MK-0457 (VX-680) show activity against the BCR-ABL1 T315I mutant kinase [63]. Unfortunately, trials for MK-0457 were suspended following the development of a cardiac arrhythmia (QTc prolongation). In spite of these options, the underlying cause of the disease remains, and efforts are underway to more fully understand both the cellular and molecular biology of BCR/ABL-induced oncogenesis. Indeed, there is increasing recognition that the current generation of anti-cancer drugs, while effective in controlling disease progression, may place the emphasis on the wrong types of cells and that greater attention should be paid to cancer stem cells [64-68]. One of the current hypotheses for the origins of $\mathrm{Ph}^{+}$leukemias is that there are populations of $\mathrm{BCR}-\mathrm{ABL}^{+} \mathrm{HSC}$ functioning as leukemic stem cells that are impervious to current drug treatments and capable of reconstituting the disease upon the cessation of treatment and/or the introduction of drug resistance mutations [65, 67, 69]. The effectiveness of future treatments for disease control and elimination will rely upon comprehensive strategies targeting signal transduction pathways in all leukemic cell types. While approaches targeting BCR-ABL oncoproteins, Src kinases, or other signaling pathways, alone and in combination, offer hope for improved therapy, only the targeted killing of leukemic stem cells offer a chance, at this stage of understanding, for a cure.

\section{Leukemic Stem Cells}

There is a growing acceptance that certain cancer cells retain properties that are reminiscent of their normal stem cell counterparts and that these characteristics enable these "cancer stem cells" (CSCs) to initiate tumorigenesis. These properties include the propensity for asymmetrical cell division to facilitate self-renewal and the ability to differentiate, albeit often in aberrant and dysfunctional ways. They also possess invasive properties and can metastasize. For $\mathrm{Ph}+\mathrm{CML}$ and B-ALL, we posit that there are discrete populations of cells that maintain certain properties that qualify them as leukemic stem cells (LSCs). These LSCs, often quiescent in nature and contained within the niche, evade detection by the immune system, are often impervious to current drug treatments, and are capable of reconstituting the disease upon the cessation of treatment and/or the introduction of drug resistance mutations [65-67]. This reservoir of LSCs is dependent upon the microenvironment established within their niche for their long-term survival and propagation [70, 71]. Perturbation of this microenvironment can alter LSC behavior and 
have profound effects on self-renewal, homing, engraftment, migration, and proliferation [70-72].

Populations of true human LSCs are typically CD34+/CD38-, quiescent, and capable of giving rise to both CD34+ and CD34- leukemic cells when transplanted into mouse recipients [73]. The cells exhibit minimal forward scatter, which is indicative of their relatively small size, and are unresponsive to cytokine stimulation in culture. Interestingly, CML LSCs are insensitive to tyrosine kinase drug inhibitors like imatinib. This property enables the reconstitution of the leukemia once treatment is ceased. This insensitivity is hypothesized to be caused one of the following mechanisms. The first explanation argues that the LSC is BCR-ABL1-dependent and can avoid drug targeting by elevated expression of BCR-ABL1 in these cells, BCR-ABL1 mutation, and/or suboptimal intracellular concentrations of imatinib. The second explanation argues that the CML LSCs at some point become independent of BCR-ABL1 due to secondary genetic changes that protect them from imatinib inhibition [73]. The ability for LSCs to escape imatinib inhibition is likely mediated through specific survival pathways. For example, in a mouse model, LSCs utilize the same Wnt/B-catenin pathways HSCs use to survive and self-renew, and these are not sensitive to BCR-ABL1 drug inhibition [74]. In another example, we have shown that BCRABL1 downregulates the tumor suppressor Pten, an important mediator in Akt signaling [75]. Its enforced expression can suppress CML LSCs, induce cell cycle arrest of leukemic cells, and slow the development of CML. It also can slow the development of B-ALL.

Taken together, these data demonstrate that a comprehensive understanding of how to target these LSC-specific pathways may ultimately prove useful in the development of targeted therapies that may potentially cure leukemias.

BCR-ABL1 requires the chaperone protein HSP90 to ensure its stability, allowing for the survival of LSCs and their progenitors. Recently, we showed using our mouse model that inhibition of HSP90 has profound effects on the BCR-ABL1 expression, resulting in a marked decrease in LSCs and progenitors. These findings were particularly helpful in that they showed that mutant BCR-ABL1 proteins, including the T315I mutant, could be destabilized and degraded, prolonging the lives of the mice. In combination with imatinib, mice possessing wildtype or T315I BCR-ABL1+ leukemic cells had even longer survivals compared to imatinib alone [76, 77].

We hypothesize that targeting genes unique to leukemic stem cell proliferation and survival, while avoiding their normal cell counterparts, may be a means to establish curative therapies for CML. Using our mouse model, we recently tested this hypothesis and identified the arachidonate 5-lipoxygenase (5-LO) gene (Alox5) as a critical regulator for LSCs in BCRABL-induced chronic myeloid leukemia (CML) [78]. In CML mice, we have previously shown that BCR-ABL1-expressing HSCs (Lin-/Sca1+/c-Kit+) function as LSCs [36]. Our DNA microarray analysis comparing these LSCs to HSCs expressing the same markers revealed several genes that were upregulated. Further, of these genes, several were not affected by imatinib treatment, indicating a kinase-independence and also a similarity to human CD34+/Lin- CML stem cells, which are also imatinib-insensitive. Foremost among these was Alox5, a known contributor to signaling pathways including p53 and PI3K, as well as other diseases [79-86]. Its distinct expression in LSCs but not HSCs made it an 
attractive target for study. In absence of Alox5, leukemic stem cells become impaired and CML cannot be propagated. A specific inhibitor of 5-lipoxygenases like Alox5, Zilueton, alone and in combination with imatinib, had profound effects on leukemic stem cell populations and dramatically prolonged the lives of the CML mice. We recently identified a population of pro-B leukemic cells (B220+/CD19+/CD43+) with stem cell characteristics [36]. Similar approaches targeting these $\mathrm{Ph}+$ stem cells would have important and potentially curative impacts for B-ALL and B cell blast crisis.

\section{The Role of the Microenvironment in CML}

Both cell-intrinsic and -extrinsic effects impact stem cell behavior and function. The microenvironment is essential to hematopoiesis, enabling homing and engraftment and facilitating stem cell function. The microenvironment for HSCs is established by their niche, which is located within the endosteal and perivascular compartments of the bone marrow, and is regulated by an assortment of signaling pathways including but not limited to those regulated by Wnt, Notch, c-Kit, BMPs, and osteopontin [72]. As with HSCs, LSCs also rely upon the microenvironment for proper homing and engraftment and overall function. Perturbations to the microenvironment have definitive effects on leukemogenesis. For example, the membrane glycoprotein CD44 plays an important role in LSC homing and engraftment in the niche. In mice lacking the $\mathrm{Cd} 44$ gene, leukemic cells fail to efficiently home and engraft to the bone marrow, and the course of CML is lengthened [71]. Similarly, in a model for acute myeloid leukemia, antibodies to CD44 disrupted LSC homing.

Together, these findings show a definitive role for the microenvironment in leukemogenesis. We have also shown a role for P-selectin and ICAM-1 in leukemogenesis [87]. In the absence of P-selectin and ICAM-1, CML progenitor cells are released from niche due to a dysfunctional interaction with bone marrow stroma. Mice succumb to CML more quickly due to pulmonary hemorrhages caused by homing of these cells to lungs, a cause of death often found in the mouse model. Lane et al. [72] propose a niche model for AML that may also apply to CML. They argue that AML LSCs infiltrate the niche and disrupt the normal HSC-niche interaction through the secretion of proteins like SCF. Under these conditions, LSCs can themselves interact with the niche and thrive, through enhanced self-renewal and proliferation. They also propose the potential development of alternative niche sites, due to the aberrant homing and engraftment properties these cells possess [72]. The microenvironment also plays an important role in Ph+ B-ALL [88]. In mice lacking the Arf tumor suppressor gene, p190 BCR-ABL1-transformed B cell progenitors become resistant to imatinib; however, when these same cells are grown in vitro, this resistance is lost, and cells are killed. This finding pointed to a role for the microenvironment in mediated $\mathrm{Ph}+\mathrm{B}-\mathrm{ALL}$ resistance to imatinib when the Arf gene is deleted. Further experimentation revealed that these cells relied upon IL7 signaling from the microenvironment to mediate their response to imatinib $[88,89]$.

In summary, although current targeted therapy for CML using BCR-ABL kinase inhibitor is highly effective in controlling the disease, a curative therapy of CML requires eradication of LSCs, and it is critical to identify key target genes/pathways in these stem cells. More indepth studies are needed to fully understand the biology of LSCs to help to identify and validate potential targets for curing CML. A plausible way to target LSCs is to use a 
combination of a BCR-ABL kinase inhibitor that suppresses leukemia cell proliferation and a compound that targets a BCR-ABL downstream gene (such as Alox5) that inhibits LSCs insensitive to the kinase inhibitors.

\section{References}

[1]. Tefferi A, Thiele J, Vardiman JW. The 2008 World Health Organization classification system for myeloproliferative neoplasms: order out of chaos. Cancer. 2009; 115:3842-7. [PubMed: 19472396]

[2]. Tefferi A, Vardiman JW. Classification and diagnosis of myeloproliferative neoplasms: the 2008 World Health Organization criteria and point-of-care diagnostic algorithms. Leukemia. 2008; 22:14-22. [PubMed: 17882280]

[3]. Vardiman JW, Thiele J, Arber DA, Brunning RD, Borowitz MJ, Porwit A, et al. The 2008 revision of the World Health Organization (WHO) classification of myeloid neoplasms and acute leukemia: rationale and important changes. Blood. 2009; 114:937-51. [PubMed: 19357394]

[4]. Zhivotovsky B, Kroemer G. Apoptosis and genomic instability. Nat Rev Mol Cell Biol. 2004; 5:752-62. [PubMed: 15340382]

[5]. Hantschel O, Superti-Furga G. Regulation of the c-Abl and Bcr-Abl tyrosine kinases. Nat Rev Mol Cell Biol. 2004; 5:33-44. [PubMed: 14708008]

[6]. Saharinen P, Vihinen M, Silvennoinen O. Autoinhibition of Jak2 tyrosine kinase is dependent on specific regions in its pseudokinase domain. Mol Biol Cell. 2003; 14:1448-59. [PubMed: 12686600]

[7]. Vainchenker W, Constantinescu SN. A unique activating mutation in JAK2 (V617F) is at the origin of polycythemia vera and allows a new classification of myeloproliferative diseases. Hematology Am Soc Hematol Educ Program. 2005:195-200. [PubMed: 16304380]

[8]. Kaushansky K. The chronic myeloproliferative disorders and mutation of JAK2: Dameshek's 54 year old speculation comes of age. Best Pract Res Clin Haematol. 2007; 20:5-12. [PubMed: 17336249]

[9]. Scott LM, Tong W, Levine RL, Scott MA, Beer PA, Stratton MR, et al. JAK2 exon 12 mutations in polycythemia vera and idiopathic erythrocytosis. N Engl J Med. 2007; 356:459-68. [PubMed: 17267906]

[10]. Chaligne R, James C, Tonetti C, Besancenot R, Le Couedic JP, Fava F, et al. Evidence for MPL W515L/K mutations in hematopoietic stem cells in primitive myelofibrosis. Blood. 2007; 110:3735-43. [PubMed: 17709604]

[11]. Chaligne R, Tonetti C, Besancenot R, Roy L, Marty C, Mossuz P, et al. New mutations of MPL in primitive myelofibrosis: only the MPL W515 mutations promote a G1/S-phase transition. Leukemia. 2008; 22:1557-66. [PubMed: 18528423]

[12]. Nowell PC, Hungerford DA. Chromosome studies on normal and leukemic human leukocytes. J Natl Cancer Inst. 1960; 25:85-109. [PubMed: 14427847]

[13]. Rowley JD. Letter: A new consistent chromosomal abnormality in chronic myelogenous leukaemia identified by quinacrine fluorescence and Giemsa staining. Nature. 1973; 243:290-3. [PubMed: 4126434]

[14]. Frohling S, Dohner H. Chromosomal abnormalities in cancer. N Engl J Med. 2008; 359:722-34. [PubMed: 18703475]

[15]. Aplan PD. Causes of oncogenic chromosomal translocation. Trends Genet. 2006; 22:46-55. [PubMed: 16257470]

[16]. Goldman JM, Melo JV. Chronic myeloid leukemia--advances in biology and new approaches to treatment. N Engl J Med. 2003; 349:1451-64. [PubMed: 14534339]

[17]. Quintas-Cardama A, Cortes J. Molecular biology of bcr-abl1-positive chronic myeloid leukemia. Blood. 2009; 113:1619-30. [PubMed: 18827185]

[18]. Demehri S, O'Hare T, Eide CA, Smith CA, Tyner JW, Druker BJ, et al. The function of the pleckstrin homology domain in BCR-ABL-mediated leukemogenesis. Leukemia. 2009 
[19]. Miroshnychenko D, Dubrovska A, Maliuta S, Telegeev G, Aspenstrom P. Novel role of pleckstrin homology domain of the Bcr-Abl protein: Analysis of protein-protein and protein-lipid interactions. Exp Cell Res. 2009

[20]. Chuang TH, Xu X, Kaartinen V, Heisterkamp N, Groffen J, Bokoch GM. Abr and Bcr are multifunctional regulators of the Rho GTP-binding protein family. Proc Natl Acad Sci U S A. 1995; 92:10282-6. [PubMed: 7479768]

[21]. Kantarjian HM, Talpaz M, Giles F, O'Brien S, Cortes J. New insights into the pathophysiology of chronic myeloid leukemia and imatinib resistance. Ann Intern Med. 2006; 145:913-23. [PubMed: 17179059]

[22]. Voncken JW, Kaartinen V, Pattengale PK, Germeraad WT, Groffen J, Heisterkamp N. BCR/ABL P210 and P190 cause distinct leukemia in transgenic mice. Blood. 1995; 86:4603-11. [PubMed: 8541551]

[23]. Lugo TG, Pendergast AM, Muller AJ, Witte ON. Tyrosine kinase activity and transformation potency of bcr-abl oncogene products. Science. 1990; 247:1079-82. [PubMed: 2408149]

[24]. Li S, Ilaria RL Jr. Million RP, Daley GQ, Van Etten RA. The P190, P210, and P230 forms of the $\mathrm{BCR} / \mathrm{ABL}$ oncogene induce a similar chronic myeloid leukemia-like syndrome in mice but have different lymphoid leukemogenic activity. J Exp Med. 1999; 189:1399-412. [PubMed: 10224280]

[25]. Pane F, Frigeri F, Sindona M, Luciano L, Ferrara F, Cimino R, et al. Neutrophilic-chronic myeloid leukemia: a distinct disease with a specific molecular marker (BCR/ABL with C3/A2 junction). Blood. 1996; 88:2410-4. [PubMed: 8839830]

[26]. Bernasconi P, Calatroni S, Boni M, Cavigliano PM, Pagnucco G, Bernasconi C. p230 does not always predict a mild clinical course in myeloid malignancies: e19a2 bcr/abl fusion transcript with additional chromosome abnormalities in a patient with acute monoblastic leukemia (M5a). Haematologica. 2001; 86:320-1. [PubMed: 11255282]

[27]. Mondal BC, Majumdar S, Dasgupta UB, Chaudhuri U, Chakrabarti P, Bhattacharyya S. e19a2 BCR-ABL fusion transcript in typical chronic myeloid leukaemia: a report of two cases. J Clin Pathol. 2006; 59:1102-3. [PubMed: 17021137]

[28]. Briz M, Vilches C, Cabrera R, Fores R, Fernandez MN. Typical chronic myelogenous leukemia with e19a2 junction BCR/ABL transcript. Blood. 1997; 90:5024-5. [PubMed: 9389724]

[29]. Emilia G, Luppi M, Marasca R, Torelli G. Relationship between BCR/ABL fusion proteins and leukemia phenotype. Blood. 1997; 89:3889. [PubMed: 9160699]

[30]. Mittre H, Leymarie P, Macro M, Leporrier M. A new case of chronic myeloid leukemia with c3/a2 BCR/ABL junction. Is it really a distinct disease? Blood. 1997; 89:4239-41. [PubMed: 9166872]

[31]. Li S. Src kinases as targets for B cell acute lymphoblastic leukaemia therapy. Expert Opin Ther Targets. 2005; 9:329-41. [PubMed: 15934919]

[32]. Li S. Src-family kinases in the development and therapy of Philadelphia chromosome-positive chronic myeloid leukemia and acute lymphoblastic leukemia. Leuk Lymphoma. 2008; 49:19-26. [PubMed: 18203007]

[33]. Danhauser-Riedl S, Warmuth M, Druker BJ, Emmerich B, Hallek M. Activation of Src kinases p53/56lyn and p59hck by p210bcr/abl in myeloid cells. Cancer Res. 1996; 56:3589-96. [PubMed: 8758931]

[34]. Meyn MA 3rd, Wilson MB, Abdi FA, Fahey N, Schiavone AP, Wu J, et al. Src family kinases phosphorylate the Bcr-Abl SH3-SH2 region and modulate Bcr-Abl transforming activity. J Biol Chem. 2006; 281:30907-16. [PubMed: 16912036]

[35]. Hu Y, Liu Y, Pelletier S, Buchdunger E, Warmuth M, Fabbro D, et al. Requirement of Src kinases Lyn, Hck and Fgr for BCR-ABL1-induced B-lymphoblastic leukemia but not chronic myeloid leukemia. Nat Genet. 2004; 36:453-61. [PubMed: 15098032]

[36]. Hu Y, Swerdlow S, Duffy TM, Weinmann R, Lee FY, Li S. Targeting multiple kinase pathways in leukemic progenitors and stem cells is essential for improved treatment of $\mathrm{Ph}+$ leukemia in mice. Proc Natl Acad Sci U S A. 2006; 103:16870-5. [PubMed: 17077147] 
[37]. Wu J, Meng F, Lu H, Kong L, Bornmann W, Peng Z, et al. Lyn regulates BCR-ABL and Gab2 tyrosine phosphorylation and c-Cbl protein stability in imatinib-resistant chronic myelogenous leukemia cells. Blood. 2008; 111:3821-9. [PubMed: 18235045]

[38]. Donato NJ, Wu JY, Stapley J, Gallick G, Lin H, Arlinghaus R, et al. BCR-ABL independence and LYN kinase overexpression in chronic myelogenous leukemia cells selected for resistance to STI571. Blood. 2003; 101:690-8. [PubMed: 12509383]

[39]. Deininger MW, Goldman JM, Melo JV. The molecular biology of chronic myeloid leukemia. Blood. 2000; 96:3343-56. [PubMed: 11071626]

[40]. Wong S, Witte ON. Modeling Philadelphia chromosome positive leukemias. Oncogene. 2001; 20:5644-59. [PubMed: 11607816]

[41]. Bernardi R, Grisendi S, Pandolfi PP. Modelling haematopoietic malignancies in the mouse and therapeutical implications. Oncogene. 2002; 21:3445-58. [PubMed: 12032781]

[42]. Wertheim JA, Miller JP, Xu L, He Y, Pear WS. The biology of chronic myelogenous leukemia:mouse models and cell adhesion. Oncogene. 2002; 21:8612-28. [PubMed: 12476308]

[43]. Daley GQ, Van Etten RA, Baltimore D. Induction of chronic myelogenous leukemia in mice by the P210bcr/abl gene of the Philadelphia chromosome. Science. 1990; 247:824-30. [PubMed: 2406902]

[44]. Kelliher MA, McLaughlin J, Witte ON, Rosenberg N. Induction of a chronic myelogenous leukemia-like syndrome in mice with v-abl and BCR/ABL. Proc Natl Acad Sci U S A. 1990; 87:6649-53. [PubMed: 2204061]

[45]. Peng C, Li S. CML mouse model in translational research. Methods Mol Biol. 2010; 602:253-66. [PubMed: 20012403]

[46]. Schindler T, Bornmann W, Pellicena P, Miller WT, Clarkson B, Kuriyan J. Structural mechanism for STI-571 inhibition of abelson tyrosine kinase. Science. 2000; 289:1938-42. [PubMed: 10988075]

[47]. Graham SM, Jorgensen HG, Allan E, Pearson C, Alcorn MJ, Richmond L, et al. Primitive, quiescent, Philadelphia-positive stem cells from patients with chronic myeloid leukemia are insensitive to STI571 in vitro. Blood. 2002; 99:319-25. [PubMed: 11756187]

[48]. Marley SB, Deininger MW, Davidson RJ, Goldman JM, Gordon MY. The tyrosine kinase inhibitor STI571, like interferon-alpha, preferentially reduces the capacity for amplification of granulocyte-macrophage progenitors from patients with chronic myeloid leukemia. Exp Hematol. 2000; 28:551-7. [PubMed: 10812245]

[49]. Druker BJ, Sawyers CL, Kantarjian H, Resta DJ, Reese SF, Ford JM, et al. Activity of a specific inhibitor of the BCR-ABL tyrosine kinase in the blast crisis of chronic myeloid leukemia and acute lymphoblastic leukemia with the Philadelphia chromosome. N Engl J Med. 2001; 344:1038-42. [PubMed: 11287973]

[50]. Kantarjian H, Jabbour E, Grimley J, Kirkpatrick P. Dasatinib. Nat Rev Drug Discov. 2006; 5:717-8. [PubMed: 17001803]

[51]. Shah NP, Nicoll JM, Nagar B, Gorre ME, Paquette RL, Kuriyan J, et al. Multiple BCR-ABL kinase domain mutations confer polyclonal resistance to the tyrosine kinase inhibitor imatinib (STI571) in chronic phase and blast crisis chronic myeloid leukemia. Cancer Cell. 2002; 2:11725. [PubMed: 12204532]

[52]. Azam M, Seeliger MA, Gray NS, Kuriyan J, Daley GQ. Activation of tyrosine kinases by mutation of the gatekeeper threonine. Nat Struct Mol Biol. 2008; 15:1109-18. [PubMed: 18794843]

[53]. Kornev AP, Haste NM, Taylor SS, Eyck LF. Surface comparison of active and inactive protein kinases identifies a conserved activation mechanism. Proc Natl Acad Sci U S A. 2006; 103:17783-8. [PubMed: 17095602]

[54]. Mian AA, Schull M, Zhao Z, Oancea C, Hundertmark A, Beissert T, et al. The gatekeeper mutation T315I confers resistance against small molecules by increasing or restoring the ABLkinase activity accompanied by aberrant transphosphorylation of endogenous BCR, even in lossof-function mutants of BCR/ABL. Leukemia. 2009; 23:1614-21. [PubMed: 19369965] 
[55]. Tokarski JS, Newitt JA, Chang CY, Cheng JD, Wittekind M, Kiefer SE, et al. The structure of Dasatinib (BMS-354825) bound to activated ABL kinase domain elucidates its inhibitory activity against imatinib-resistant ABL mutants. Cancer Res. 2006; 66:5790-7. [PubMed: 16740718]

[56]. Talpaz M, Shah NP, Kantarjian H, Donato N, Nicoll J, Paquette R, et al. Dasatinib in imatinibresistant Philadelphia chromosome-positive leukemias. N Engl J Med. 2006; 354:2531-41. [PubMed: 16775234]

[57]. Shen T, Kuang YH, Ashby CR, Lei Y, Chen A, Zhou Y, et al. Imatinib and nilotinib reverse multidrug resistance in cancer cells by inhibiting the efflux activity of the MRP7 (ABCC10). PLoS One. 2009; 4:e7520. [PubMed: 19841739]

[58]. Klejman A, Schreiner SJ, Nieborowska-Skorska M, Slupianek A, Wilson M, Smithgall TE, et al. The Src family kinase Hck couples BCR/ABL to STAT5 activation in myeloid leukemia cells. EMBO J. 2002; 21:5766-74. [PubMed: 12411494]

[59]. Stanglmaier M, Warmuth M, Kleinlein I, Reis S, Hallek M. The interaction of the Bcr-Abl tyrosine kinase with the Src kinase Hck is mediated by multiple binding domains. Leukemia. 2003; 17:283-9. [PubMed: 12592324]

[60]. Warmuth M, Bergmann M, Priess A, Hauslmann K, Emmerich B, Hallek M. The Src family kinase Hck interacts with Bcr-Abl by a kinase-independent mechanism and phosphorylates the Grb2-binding site of Bcr. J Biol Chem. 1997; 272:33260-70. [PubMed: 9407116]

[61]. O'Hare T, Walters DK, Stoffregen EP, Jia T, Manley PW, Mestan J, et al. In vitro activity of BcrAbl inhibitors AMN107 and BMS-354825 against clinically relevant imatinib-resistant Abl kinase domain mutants. Cancer Res. 2005; 65:4500-5. [PubMed: 15930265]

[62]. Fava C, Kantarjian H, Cortes J, Jabbour E. Development and targeted use of nilotinib in chronic myeloid leukemia. Drug Design, Development, and Therapy. 2008; 2:233-43.

[63]. Giles FJ, Cortes J, Jones D, Bergstrom D, Kantarjian H, Freedman SJ. MK-0457, a novel kinase inhibitor, is active in patients with chronic myeloid leukemia or acute lymphocytic leukemia with the T315I BCR-ABL mutation. Blood. 2007; 109:500-2. [PubMed: 16990603]

[64]. Passegue E. Cancer biology: a game of subversion. Nature. 2006; 442:754-5. [PubMed: 16915276]

[65]. Huntly BJ, Gilliland DG. Cancer biology: summing up cancer stem cells. Nature. 2005; 435:1169-70. [PubMed: 15988505]

[66]. Huntly BJ, Gilliland DG. Leukaemia stem cells and the evolution of cancer-stem-cell research. Nat Rev Cancer. 2005; 5:311-21. [PubMed: 15803157]

[67]. Michor F, Hughes TP, Iwasa Y, Branford S, Shah NP, Sawyers CL, et al. Dynamics of chronic myeloid leukaemia. Nature. 2005; 435:1267-70. [PubMed: 15988530]

[68]. Roeder I, Horn M, Glauche I, Hochhaus A, Mueller MC, Loeffler M. Dynamic modeling of imatinib-treated chronic myeloid leukemia: functional insights and clinical implications. Nat Med. 2006; 12:1181-4. [PubMed: 17013383]

[69]. Jamieson CH. Chronic myeloid leukemia stem cells. Hematology Am Soc Hematol Educ Program. 2008; 436:42.

[70]. Jin L, Hope KJ, Zhai Q, Smadja-Joffe F, Dick JE. Targeting of CD44 eradicates human acute myeloid leukemic stem cells. Nat Med. 2006; 12:1167-74. [PubMed: 16998484]

[71]. Krause DS, Lazarides K, von Andrian UH, Van Etten RA. Requirement for CD44 in homing and engraftment of BCR-ABL-expressing leukemic stem cells. Nat Med. 2006; 12:1175-80. [PubMed: 16998483]

[72]. Lane SW, Scadden DT, Gilliland DG. The leukemic stem cell niche: current concepts and therapeutic opportunities. Blood. 2009; 114:1150-7. [PubMed: 19401558]

[73]. Jorgensen HG, Holyoake TL. Characterization of cancer stem cells in chronic myeloid leukaemia. Biochem Soc Trans. 2007; 35:1347-51. [PubMed: 17956348]

[74]. Hu Y, Chen Y, Douglas L, Li S. beta-Catenin is essential for survival of leukemic stem cells insensitive to kinase inhibition in mice with BCR-ABL-induced chronic myeloid leukemia. Leukemia. 2009; 23:109-16. [PubMed: 18818703]

[75]. Peng C, Chen Y, Yang Z, Zhang H, Osterby L, Rosmarin AG, et al. PTEN is a tumor suppressor in CML stem cells and BCR-ABL induced leukemias in mice. Blood. 2009 
[76]. Peng C, Brain J, Hu Y, Goodrich A, Kong L, Grayzel D, et al. Inhibition of heat shock protein 90 prolongs survival of mice with BCR-ABL-T315I-induced leukemia and suppresses leukemic stem cells. Blood. 2007; 110:678-85. [PubMed: 17395781]

[77]. Peng C, Li D, Li S. Heat shock protein 90: a potential therapeutic target in leukemic progenitor and stem cells harboring mutant BCR-ABL resistant to kinase inhibitors. Cell Cycle. 2007; 6:2227-31. [PubMed: 17671436]

[78]. Chen Y, Hu Y, Zhang H, Peng C, Li S. Loss of the Alox5 gene impairs leukemia stem cells and prevents chronic myeloid leukemia. Nat Genet. 2009; 41:783-92. [PubMed: 19503090]

[79]. Catalano A, Rodilossi S, Caprari P, Coppola V, Procopio A. 5-Lipoxygenase regulates senescence-like growth arrest by promoting ROS-dependent p53 activation. EMBO J. 2005; 24:170-9. [PubMed: 15616590]

[80]. Chen XS, Sheller JR, Johnson EN, Funk CD. Role of leukotrienes revealed by targeted disruption of the 5-lipoxygenase gene. Nature. 1994; 372:179-82. [PubMed: 7969451]

[81]. Radmark O, Werz O, Steinhilber D, Samuelsson B. 5-Lipoxygenase: regulation of expression and enzyme activity. Trends Biochem Sci. 2007; 32:332-41. [PubMed: 17576065]

[82]. Taylor PM, Woodfield RJ, Hodgkin MN, Pettitt TR, Martin A, Kerr DJ, et al. Breast cancer cellderived EMMPRIN stimulates fibroblast MMP2 release through a phospholipase A(2) and 5lipoxygenase catalyzed pathway. Oncogene. 2002; 21:5765-72. [PubMed: 12173047]

[83]. Zhao L, Moos MP, Grabner R, Pedrono F, Fan J, Kaiser B, et al. The 5-lipoxygenase pathway promotes pathogenesis of hyperlipidemia-dependent aortic aneurysm. Nat Med. 2004; 10:96673. [PubMed: 15322539]

[84]. Wymann MP, Schneiter R. Lipid signalling in disease. Nat Rev Mol Cell Biol. 2008; 9:162-76. [PubMed: 18216772]

[85]. Yokomizo T, Izumi T, Shimizu T. Leukotriene B4: metabolism and signal transduction. Arch Biochem Biophys. 2001; 385:231-41. [PubMed: 11368003]

[86]. Soberman RJ, Christmas P. The organization and consequences of eicosanoid signaling. J Clin Invest. 2003; 111:1107-13. [PubMed: 12697726]

[87]. Pelletier SD, Hong DS, Hu Y, Liu Y, Li S. Lack of the adhesion molecules P-selectin and intercellular adhesion molecule-1 accelerate the development of BCR/ABL-induced chronic myeloid leukemia-like myeloproliferative disease in mice. Blood. 2004; 104:2163-71. [PubMed: 15213099]

[88]. Dorshkind K, Witte ON. Linking the hematopoietic microenvironment to imatinib-resistant $\mathrm{Ph}+$ B-ALL. Genes Dev. 2007; 21:2249-52. [PubMed: 17875661]

[89]. Williams RT, den Besten W, Sherr CJ. Cytokine-dependent imatinib resistance in mouse BCRABL+, Arf-null lymphoblastic leukemia. Genes Dev. 2007; 21:2283-7. [PubMed: 17761812] 
A

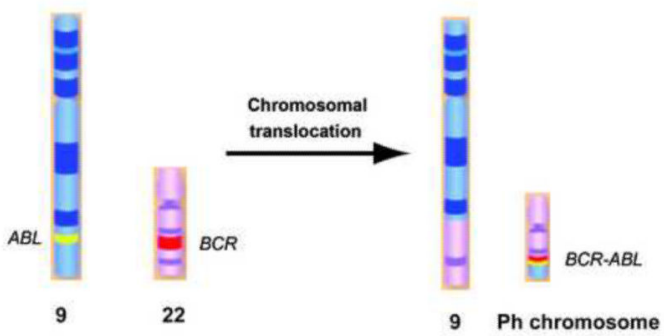

B
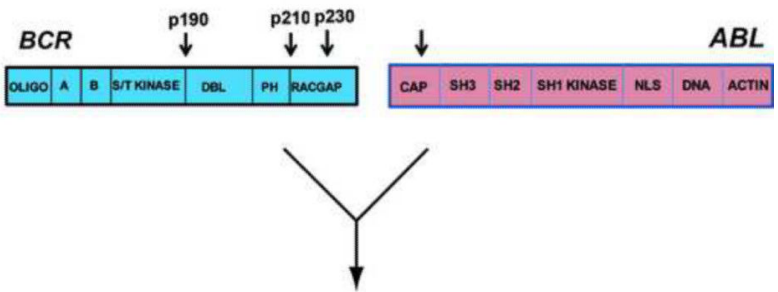

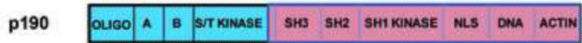

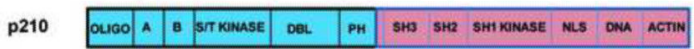

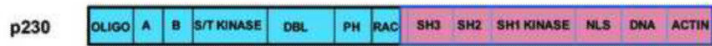

Figure 1.

Biochem Pharmacol. Author manuscript; available in PMC 2015 May 21. 


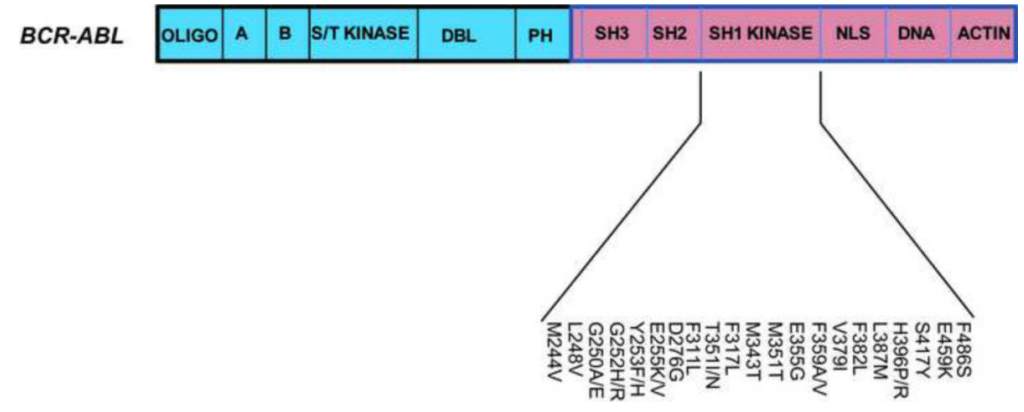

Figure 2. 


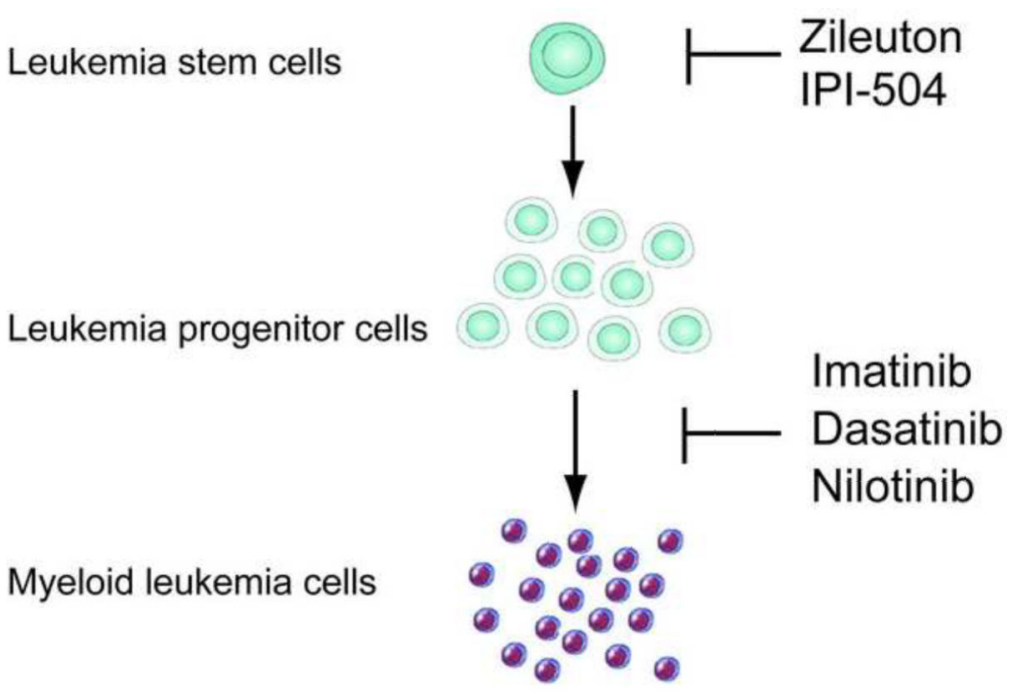

Figure 3. 